\title{
Chapter 9 \\ Moral Responsibility and the Justification of Policies to Preserve Antimicrobial Effectiveness
}

\author{
Alberto Giubilini and J. Savulescu
}

\begin{abstract}
Restrictive policies that limit antimicrobial consumption, including therapeutically justified use, might be necessary to tackle the problem of antimicrobial resistance. We argue that such policies would be ethically justified when forgoing antimicrobials constitutes a form of easy rescue for an individual. These are cases of mild and self-limiting infections in otherwise healthy patients whose overall health is not significantly compromised by the infection. In such cases, restrictive policies would be ethically justified because they would coerce individuals into fulfilling a moral obligation they independently have. However, to ensure that such justification is the strongest possible, states also have the responsibility to ensure that forgoing antimicrobials is as easy as possible for patients by implementing adequate compensation measures.
\end{abstract}

Keywords Bioethics $\cdot$ Public health ethics Antimicrobial resistance $\cdot$ Collective responsibility $\cdot$ Easy rescue

\footnotetext{
A. Giubilini $(\bowtie)$

Wellcome Centre for Ethics and Humanities, University of Oxford, Oxford, UK

Oxford Uehiro Centre for Practical Ethics, University of Oxford, Oxford, UK

e-mail: alberto.giubilini@philosophy.ox.ac.uk

J. Savulescu

Oxford Uehiro Centre for Practical Ethics, University of Oxford, Oxford, UK

Visiting Professorial Fellow in Biomedical Ethics, Murdoch Children's Research Institute, Melbourne, Australia

Distinguished Visiting Professor on Law, Melbourne Law School, University of Melbourne, Melbourne, Australia 


\subsection{The Problem of Antimicrobial Resistance}

When Alexander Fleming was awarded the Nobel Prize for Medicine in 1945, he warned in his acceptance speech of the risk that some bacteria could develop resistance to penicillin, which he had discovered 17 years earlier. It cannot be overstated how longsighted Fleming was. Today, "bacteria are resistant to nearly all antibiotics that were earlier active against them" (Herrmann and Laxminarayan 2010, p. 4.2), and "700,000 people die of resistant infections every year" (O'Neill 2016, p. 4). As estimated by the Review on Antimicrobial Resistance commissioned by the UK government, "by 205010 million lives a year are at risk due to drug resistant infections, as are 100 trillion USD of economic output" (O'Neill 2016). Examples of diseases associated with antimicrobial resistance (AMR) include tuberculosis, gonorrhoea, typhoid fever, and group A streptococcus (Van der Velden et al. 2013). The problem of AMR has been framed by some in terms of a "slowly emerging disaster" (Littmann and Viens 2015) and of a "global health security issue" (Balasegaram et al. 2015).

AMR is a naturally occurring phenomenon: microbes naturally tend to adapt to antimicrobials and develop resistance. However, AMR is accelerated by human behaviour (Jamrozik and Selgelid 2019), and particularly the use and abuse of antimicrobials, both in livestock (Anomaly 2019; Giubilini et al. 2017; O'Neill 2015; Anomaly 2009) and in humans (O'Neill 2016). This paper is focussed on AMR caused by human consumption of antimicrobials, and therefore on the human factor in the development of AMR. There is a positive correlation between antimicrobial resistance rates and antimicrobial consumption in humans (Van der Velden et al. 2013 , pp. 318-19). In fact, in the case of antibiotics, it is now widely accepted that "the use of antibiotics is the single most important factor leading to antibiotic resistance around the world: simply using antibiotics creates resistance" (CDC, About antimicrobial resistance), even when antibiotic use is medically indicated to treat infections (which is what makes AMR a particularly difficult ethical issue). Thus, the paradox of antibiotic and certain other kind of antimicrobial consumption is that while certain antimicrobials can be beneficial to individuals, their use also poses a threat to public health, to the lives of millions of people, and to the world economy. If they are not used more wisely than they currently are, i.e. if their consumption is not reduced, we might face a "post antibiotic" era (Alanis 2005; WHO 2014) characterized by two undesirable outcomes. First, we might no longer have effective means of treating severe infections. Second, medicine's achievements that require effective antibiotics, such as organ transplantation, cancer chemotherapy, and major surgery, might no longer be available (WHO, Antimicrobial resistance).

To be sure, the problem of reducing antibiotic and certain type of antimicrobial consumption mainly concerns those countries with easy access to and massive consumption of antimicrobials. These are mainly high-income countries (HICs). The consumption rate of antimicrobials in most low- and middle-income countries (LMICs), although it increased dramatically in recent years, remains much lower than that in HICs, and in many LMICs the burden of infectious disease still outweighs the burden of resistance; the increase in consumption in such countries 
ought to be closely monitored, but drastic measures to reduce antibiotic consumption need to be implemented primarily in HICs (Klein et al. 2018). Reduction of therapeutically justified antimicrobial consumption in LMICs for conservation purposes might have undesirable outcomes, especially in those countries where the level of public health is already poor. There might be exceptions, of course; for instance, India is a lower-income country and one of the major contributors to resistance through very high consumption rates (Kumar et al. 2013; WHO India 2018), so perhaps significant restrictions on antibiotic access - that is, restrictions that apply also to therapeutically justified use - should be implemented in such context as well. However, to make our arguments the least controversial possible, we take them to apply only to HICs where a good level of public health might allow leaving certain mild and self-limiting infections untreated without posing significant costs on patients.

This paper is focussed on two often neglected aspects of the problem of AMR, namely on the individual moral obligations with regard to antimicrobial consumption and on the type of justification that health authorities could and should offer for restricting access to antimicrobials in order to preserve antimicrobial effectiveness. As we will argue in Sect. 9.3, these two aspects are closely related: the state has an obligation to provide the strongest justification possible for restrictive interventions aimed at limiting antimicrobial consumption, and the strongest justification is one based on the existence of an individual moral obligation to forgo antimicrobials, perhaps (as we will suggest in Sect. 9.4) even in case of mild self-limiting infections that do not significantly risk worsening the individual's general health. The fact that even justified use of antimicrobials, i.e. the use that is medically necessary to treat infections (as opposed to unjustified use, e.g. when antibiotics are prescribed for viral infections, a practice that is not uncommon unfortunately), contributes to antimicrobial resistance determines a moral conflict between individual interest and collective interest that might require individuals to make sacrifices for the sake of the common good.

Such moral conflict gives rise to a "tragedy of the commons" scenario (Hollis and Maybarduk 2015), which will be presented in Sect. 9.2: we will argue, following Garrett Hardin, that the tragedy of the commons has an ethical solution, which will be presented in Sect. 9.4, where we will argue that there is a moral obligation to contribute to the preservation of the common good of antimicrobial effectiveness which might entail a moral obligation not to use antimicrobials in some cases of mild, self-limiting infections, provided that certain conditions obtain and that the state takes all the measures that are necessary to ensure that forgoing antimicrobials in those cases approximates a form of "easy rescue".

Thus, in Sect. 9.4 we will draw the policy implications of this ethical solution to the tragedy of the commons: the moral obligation to sometimes forgo antimicrobials, grounded in a duty of easy rescue, strengthens the justification for state interventions that prohibit or discourage the use of antimicrobials in certain cases. Since states should be able to provide the strongest justification possible for implementing restrictive policies that discourage or prohibit antimicrobial consumption, appeal to individual moral obligations to sometimes forgo antimicrobials has a political weight in terms of justification of state-imposed restrictions on antimicrobial use. 
However, as we will suggest in conclusion of Sect. 9.4, the moral obligation of the state to provide the strongest justification possible for restricting access to antimicrobials implies an obligation on the state to ensure that forgoing antimicrobials does represent a form of easy rescue, i.e. that individuals bear as small a cost as possible for leaving certain infections untreated with antimicrobials (assuming this measure is necessary). This means, in practice, that the state has moral obligations towards individuals who are requested to forgo antimicrobial for the sake of the collective good, such as the obligation to provide enhanced medical follow up and to adequately compensate, financially or in other ways (e.g. higher priorities on waiting lists for other medical treatments), these individuals.

\subsection{Public Goods, Tragedy of the Commons, and Policies to Address Antimicrobial Resistance}

It has been claimed that "if effective antibiotics are seen as a public good, their overuse may be likened to the tragedy of the commons scenario" (Littmann and Viens 2015, p. 214). This statement is not entirely correct in the way the notion of 'public good' is applied. As we are going to see in this section, antibiotic and more generally antimicrobial effectiveness shares an essential feature with common goods or common pool resources, rather than with public goods. Let's see more in detail what this terminology means when the concepts of "public goods" and of "common goods" are applied to the case of antimicrobial effectiveness.

Some benefits associated with antimicrobial effectiveness can certainly be considered public goods. These include freedom from infectious diseases (Selgelid 2007, p. 226), the containment of infectious diseases (Woodward and Smith 2003, p. 10), or the reduced risk of infection by a resistant disease (Smith and Coast 2003,

p. 78). These benefits are public goods in the technical sense of the term: they are non-excludable, in the sense that people cannot be excluded from benefitting from them; and they are non-rivalrous, in the sense that the fact that a person benefits from them does not affect the way and the extent to which others benefit as well (Cowen 2008). More precisely, freedom from infectious diseases, infectious disease containment, and the reduced risk of infection can be conceived as global public goods, i.e. goods "exhibiting a significant degree of publicness (i.e. non-excludability and non-rivalry) across national boundaries" (Woodward and Smith 2003, p, 8).

Effective antimicrobials are the means through which such public goods are preserved. But antimicrobial effectiveness is a common good rather than a public good because antimicrobial effectiveness is rivalrous in consumption, in virtue of what Anne Schwenkenbecher in a chapter of this volume calls "the antimicrobial footprint" of antimicrobial consumptions: "simply using antibiotics [or other antimicrobials] creates resistance" (CDC, About Antimicrobial resistance) and "more consumption of antibiotics directly leads to more resistance" (O'Neill 2016, p. 17), regardless of whether antimicrobial use is therapeutically justified or not. The use of the resource of antimicrobial effectiveness through antimicrobial consumption erodes 
the resource and therefore diminishes its availability. As put by Jonny Anomaly, "individually rational choices produce substantial social costs by creating reservoirs of antibiotic-resistant bacteria in human hosts and more generally in our shared microbial environment" (Anomaly 2013, p. 753). It is important to point out that, while antimicrobial use might benefit individuals in the short term, this is not necessarily the case in the long term: individuals can incur a portion of the costs associated with antimicrobial resistance (Anomaly 2013, p. 752). For example, the individual who takes antibiotics can become a carrier of resistant bacteria, which means that the individual is at greater risk in case of subsequent infections (Cars et al. 2008).

It has been observed that the effectiveness of antimicrobials can "be modelled as a natural resource in much the same way as are fish, tree, oil, and other resources" (Herrmann and Laxminarayan 2010, p. 4.3). According to John Conly, for example,

antimicrobial resistance may be likened to [the] overfishing scenario, to cattle overgrazing the grass in the commons or to deforestation on Easter Island, which led to population dying out. Antimicrobial resistance is a consequence of continued overuse of antibiotics combined with the constant growth of resistance overtime. (WHO 2010)

Typically, consumption of natural resources determines a 'tragedy of the commons' scenario (Ostrom et al. 1999,). Garrett Hardin first described the "tragedy of the commons" in an article he published in Science (Hardin 1968). Hardin illustrated the problem through the example of a commons to which some herdsmen have access. The tragedy occurs when many herdsmen, acting merely out of self-interest, have their cattle overgraze the commons, thus eroding the resource (Hardin 1968, p. 1244). Particularly in a context of growing population, all herdsmen acting in the same way deplete the common good. In the context of antimicrobial effectiveness, the same problem arises (Hollis and Maybarduk 2015). As Jonny Anomaly put it, "the benefits of [antibiotic] use are borne by the individual, the costs are socialised, and the consequent harm is the product of many independent actions" (Anomaly 2013, p. 752).

According to Hardin, one characteristic of a tragedy of the commons is the fact that there is no "technical" solution to the problem, meaning that there is no solution "that requires a change only in the techniques of the natural sciences, demanding little or nothing in the way of change in human values or ideas of morality" (Hardin 1968, p. 1243). On the contrary, Hardin argued, the solution requires a "fundamental extension" of our morality (Hardin 1968, p. 1243), i.e. acting in view of protecting the public interest rather than in a merely self-interested way.

However, Hardin seemed to be sceptical about the possibility that such an extension of morality could occur, at least without some external coercive intervention (which on most accounts of morality would arguably undermine the authentically "moral" nature of the change invoked). He believed that the best way to solve a tragedy of the commons is through some degree of "mutually agreed upon" coercion (Hardin 1968, p. 1247), for example in the form of taxation that would allow to internalize the negative externalities of individual consumption. ${ }^{1}$

\footnotetext{
${ }^{1}$ Another solution Hardin proposed is the privatization of the commons (Hardin 1968, p. 1245), which in the case of antimicrobials might consist in "extending the period of exclusivity, possibly
} 
And indeed, some have suggested that the negative externalities of antimicrobial use could be internalised through the introduction of user fees or consumption taxes (Littmann and Viens 2015; Anomaly 2013; Herrmann and Laxminarayan 2010). Internalization is typically achieved by "taxing negative externalities (...) at a rate that would offset the social cost of the activities that generate the externalities, and then (ideally) using the revenues from the tax to fund socially useful projects" (Anomaly 2009, p. 433). The idea behind the concept of internalization is that it is those who are responsible for a negative externality that should bear the cost for it.

However, it might not be possible to fully internalise the collective cost of antimicrobial consumption and to disincentivize consumers through a tax: selection for AMR will probably continue to occur in spite of the tax and in spite of the investment of the revenue in strategies to contain AMR such as research on new antimicrobials. For this reason, it has been suggested that we might need at some point to introduce policies to restrict antimicrobial use only to the most serious infections, i.e. that it might be necessary to prevent, if necessary through legal prohibition, their use in the case of milder self-limiting infections (Foster and Grundmann 2006, p. 179). We will return to this point in Sect. 9.4.

Policies might therefore aim to disincentivize individuals from using antimicrobials, in the case of taxation; or they might coercively impose restrictions on antimicrobial use, in the case of outright prohibition of antimicrobial use in certain circumstances. As said before, we are interested here not so much in determining which policies would be more effective and ethically acceptable. Thus, we do not intend to provide arguments for or against taxation of antibiotics or restrictions on their use. Rather, we are interested in what justification an authority might offer for implementing restrictive policies, whatever form they take. While such policies might be justified by considerations of public interest, it is important that the type of justification that a state can provide for interventions that limit or discourage antimicrobial use be the strongest justification possible, given that such interventions might require individuals to sacrifice some significant personal interest, such as the interest in accessing effective health care, for the sake of the common good. As we are going to argue in the next section, considerations about the morality of individual choices regarding antimicrobial consumption can strengthen the justification for such policies.

\subsection{Morality and Antimicrobial Consumption}

Restrictive and coercive interventions might be efficacious at protecting the common goods associated with AMR containment and in preserving the common good of antimicrobial effectiveness. However, the "tragedy of the commons" scenario

indefinitely" of the patents, thus giving "the patentee the ability to charge high prices and thus indirectly restrain overuse by some users" (Hollis and Maybarduk 2015, p. 33). 
which preservation of antimicrobial effectiveness gives rise to suggests that there is an independent ethical dimension to the problem of AMR. In this section we will explain why discussing such an independent ethical dimension is important from a political point of view, i.e. in view of justifying coercive policies aimed at restricting antimicrobial use.

Establishing an independent moral responsibility to make a more appropriate use of antimicrobials would make the justification that a state could provide for policies that restrict or discourage antimicrobial use the strongest possible. And, arguably, the state does have a duty to provide individuals with the strongest justification possible for implementing policies that restrict or discourage a treatment that is in the individuals' best interest, as is often the case with antimicrobials.

Restrictive policies might be justified in light of a state's duty to protect certain common goods and public goods, such as the public goods associated with AMR containment. These possible interventions range from those that are minimally intrusive to those that more substantially infringe rights or important interests of individuals. Thus, at one end of the spectrum we find policies such as information campaigns, nudging, or incentivisation of certain pro-social behaviours; and at the other end we find more restrictive policies such as taxation and compulsion. In all such cases, the authority enforcing such policies should be able to provide the strongest justification possible for its interventions, but the more restrictive the policies become, the more difficult it is for the authority to meet such requirement. A state's duty to protect public goods and common goods by itself does not provide the strongest justification possible for interventions that sacrifice important individual interests. The justification would be stronger if, in addition to considerations of public interest, there were independent individual moral obligations to make those individual sacrifices that are required by the restrictive policy (Giubilini et al. 2018) Thus, one way to strengthen the justification for state interventions such as taxation of antimicrobials or prohibition of certain antimicrobial uses is to identify a preexisting individual moral obligation not to use antimicrobials in certain cases. Such independent moral obligation to prioritize other-regarding choices over selfinterested choices would make the case for introducing restrictive policies that limit or discourage antimicrobial use as compelling as possible: such policies would simply impose or encourage choices that individuals have an independent moral obligation to make anyway.

\subsection{Individual Responsibility and Duty of Easy Rescue: The Ethical Solution to the Tragedy of the Commons and the Responsibilities of the State}

We have noted above that, as Hardin himself acknowledged, the tragedy of the commons is first and foremost an ethical problem. Therefore, it has an ethical solution that is independent from the justification for legislative coercive solutions. Now, 
"ethical solution" means, according to Hardin's phrasing, a change in "human values" informing human behaviour. Thus, in the case of antimicrobial consumption, the ethical solution to the tragedy of the commons consists in justifying the existence of an individual moral obligation to act contrary to one's (short term) self interest in order to contribute to the preservation of the common good of antimicrobial effectiveness. In other words, the ethical solution consists in finding a justification for a moral duty not to use antimicrobials, if necessary even at the cost of leaving some infections untreated, in order to protect the common good of antimicrobial effectiveness. In this section we are going to provide this justification.

It is plausible to assume that individuals have what might be called a "duty of easy rescue" (Savulescu 2007). That is, if doing X (or refraining from doing Y) entails a small cost to an individual and a large benefit (or prevention of a large harm) to others, the individual has a clear prima facie moral obligation to do X (or to refrain from doing Y). Morality is essentially different from prudence, and requires the sacrifice of one's own interests for others. It is debatable what kind of individual sacrifices morality requires, but if morality requires anything, almost everyone would agree that it certainly requires at least small sacrifices for the sake of preventing great harm. This does not mean that an individual does not have a moral obligation when the cost to her is not small. However, in easy rescue case, such moral obligation seems uncontroversial. A formulation of the duty of easy rescue was famously provided by Peter Singer, according to whom "if it is in our power to prevent something bad from happening, without thereby sacrificing anything of comparable moral importance, we ought, morally, to do it" (Singer 1972, p. 230, emphasis added). A roughly equivalent, though way less demanding, formulation has been provided by Tim Scanlon, according to whom "[i]f we can prevent something very bad from happening to someone by making a slight or even moderate sacrifice, it would be wrong not to do so" (Scanlon 1998, p. 224). The fact that some version of a duty of easy rescue can be defended both from a utilitarian perspective- in the case of Singer - and a contractualist perspective- in the case of Scanlon - supports the idea that it is a fundamental requirement of morality on which reasonable people could agree.

The existence of a duty of easy rescue implies an individual moral obligation to forgo antimicrobials for the sake of the common good of antimicrobial effectiveness, when forgoing antimicrobials comes at a sufficiently small cost to individuals. This would be the case, for example, when antimicrobials are not necessary to treat an infection (for example in the case of viral infections), in which case there would be no cost at all in forgoing antimicrobials. But forgoing antimicrobials would also come at a relatively small cost to individuals when individuals have minor selflimiting infections or low risk mild infections (for example, skin infections which could be treated topically with antiseptics) that do not significantly worsen the general state of health of the individual, where the risks of complications is adequately monitored, and when the individual is adequately compensated for any financial and non-financial cost she might incur as a consequence of leaving that infection untreated. As some have suggested (Foster and Grundmann 2006) it might at some 
point be necessary to leave such self-limiting infections untreated in order to preserve antimicrobial effectiveness.

The moral duty of easy rescue represents the ethical solution to the tragedy of the commons in the context of antimicrobial consumption that Hardin advocated: individuals have a moral obligation to prioritize the public interest in the preservation of the commons of antimicrobial effectiveness over their own interest in treating with antimicrobials any type of infection (including mild and self-limiting ones), because doing so comes at a small cost to individuals, at least when all that is required of individuals is to leave self-limiting mild or minor infections untreated in circumstances in which this would not significantly worsen individual health and where adequate compensatory measures are in place.

Now, since it is necessary that a large number of individuals fulfil a duty of easy rescue in order for a public benefit to obtain, we can say that there is not only an individual, but also a collective responsibility to forgo antimicrobials when doing so is a way of fulfilling a duty of easy rescue. Now, in some cases of collective action, any individual contribution to a collective good, or to the prevention of a collective harm, is insignificant; for example, the contribution each individual could make to the realisation of herd immunity through individual vaccination, or the contribution each individual could make to the prevention of global warming by avoiding driving just for fun, are both negligible. However, in the case of containment of antimicrobial resistance every single individual forgoing antimicrobials could make a difference, because every single individual could become the carrier of resistant microbes that are then passed onto other people. For example, it has been shown that individuals who take antibiotics for respiratory and urinary infections might develop bacterial resistance that could last up to 12 months (Costelloe et al. 2010). Thus, the need to preserve the common good of antimicrobial effectiveness implies not only a collective responsibility, but also an individual responsibility not to use antimicrobials so as to benefit others by contributing to the preservation of antimicrobial effectiveness, at least as long as forgoing antimicrobials comes at a small enough cost to individuals.

When forgoing antimicrobials is a moral duty of easy rescue, we can claim that the state is in the position to fulfil its obligation to provide the strongest justification possible for prohibiting or at least discouraging the use of antimicrobials: as we said in Sect. 9.3, the state would be discouraging or preventing individuals from doing only what they have a moral obligation not to do anyway. Therefore, being the state in the position to fulfil its moral obligations in implementing restrictive measures, such restrictive measures regarding antimicrobial use are ethically justified. As one of us put it, "when the cost to us of forgoing some activity is small (...) and the harm to others which thereby does not occur is great (prevention of serious disease), then liberals might require that the state prevent this harm" (Savulescu 2007, p. 10).

"Duty to rescue" laws exist in many European countries; for instance, in Germany and France it is illegal not to assist a person in danger when providing assistance entails a small or no risk to the potential rescuer. From what we have said so far, laws restricting antimicrobial use could be ethically justified as special cases of "duty to rescue" laws of this kind. 
The individual moral responsibility to forgo antimicrobials in certain circumstances implies that there are two other actors with specific moral responsibilities, besides patients with minor or mild self-limiting infections.

First, doctors have the responsibility to assess whether a certain infection is selflimiting and, more in general, whether leaving a certain infection untreated is compatible with a good enough level of individual health. In one important sense, the fact that the state has the strongest justification possible for imposing bans on antimicrobial use or for discouraging through taxation antimicrobial consumption takes the responsibility for decisions about antimicrobial prescription out of the hands of doctors: if a certain infection is mild and self limiting and leaving it untreated does not significantly worsen the general state of health of the patient, then the state, rather than the doctor, is justified in preventing the use of antimicrobials for the sake of the common good. However, the doctors would still have the important responsibility of determining whether the conditions specified in such laws would apply, and thus they would still be the ultimate gate-keepers of antimicrobials.

Second, but equally important, healthcare systems and states have important moral responsibilities too. We have said that having an uncontroversial individual moral obligation based on a duty of easy rescue to sometimes forgo antimicrobials strengthens the justification for state interventions that forbid or discourage antimicrobial use. Therefore, the state or the healthcare system have the responsibility to ensure that forgoing antimicrobials does represent a form of easy rescue, i.e. that it is not too burdensome for patients, so that the justification for state intervention is the strongest possible. This means, at the very least, that patients who are denied antimicrobials should be carefully monitored and provided with adequate and enhanced medical follow up to make sure that forgoing antimicrobial treatment does not significantly worsen the general state of health of the individual. It is the responsibility of states and of healthcare systems to ensure that adequate measures are in place in order to guarantee monitoring and medical supervisions of those patients who sacrifice their self-interest for the sake of the collective good, so that their sacrifice would represent a form of easy rescue.

However, we claim that the responsibility of states extends beyond the provision of medical supervision and follow up. We propose that a further measure that might be implemented in order to ensure that the rescue is an easy rescue is that of compensating individuals who make a sacrifice for the sake of the collective good. Compensation - financial or of other kind - would be an appropriate measure because it would provide individuals with an additional reason for forgoing antimicrobials in certain circumstances, it would be fair in consideration of the sacrifice individuals are making for the sake of the collective good, and, more importantly, if the right type of compensation is offered, it could make their condition easier to bear, thus approximating a form of easy rescue and providing a further reason for the existence of an individual ethical obligation. For example, those who forgo antimicrobials and leave infections untreated could be offered first call on future medical treatments, even for conditions that are not related to the current infection; or 
they might be offered discounts when they buy other medicines, such as painkillers, or discounts on future medical treatments; alternatively, they might be offered outright financial compensation, for example in the form of tax relief or by directly paying them, which would account for any financial loss that might result from enduring a prolonged infections. In this way, they would derive at least some benefit from the sacrifice they are making, which would render the sacrifice easier to bear, and at the same time society would be "making up" for the sacrifice it is imposing on these individuals.

Granted, preserving antimicrobial effectiveness by financially compensating those who forgo antimicrobials might involve a significant cost for the state. However, we saw in the introduction that there will be significant costs associated with AMR if we don't intervene now; therefore, investing money now to compensate and to guarantee adequate medical follow up to those who make sacrifices in order to contain AMR might be a good strategy also from the point of view of cost-effectiveness.

\subsection{Conclusions}

When is it necessary to leave infections untreated in order to preserve the common good of antimicrobial effectiveness? This is an empirical issue and the answer depends on whether and to what extent the societal optimum of antimicrobial consumption differs from the individual optimum. In other words, it concerns the issue whether and to what extent the level of individual consumption that is consistent with satisfactory AMR containment (the societal optimum) differs from the level of consumption that would effectively treat infections in any individual (the individual optimum). As Kevin Foster and Hajo Grundmann (2006, pp. 178-9) have explained, if individual and societal optima were similar, it would be sufficient to avoid inappropriate antimicrobial use, such as using antibiotics in the case of viral infections, an abuse which often occurs (Van der Velden et al. 2013). Only inappropriate use of antimicrobials would then be morally impermissible. However, if individuals and societal optimum differed significantly, in order to protect the societal interest in AMR containment individuals might be required to leave minor and mild selflimiting infections untreated in order to reserve antimicrobials for serious major infections. In such cases, coercive policies that restrict access to some therapeutically justified use of antimicrobials are ethically permissible, or so we have argued. However, when implementing such restrictive policies, state and health authorities have responsibilities not only towards the collective, but also towards individuals who make (small) sacrifices for the sake of the collective interested, and who should be guaranteed adequate compensation in exchange for leaving certain infections untreated. 
Acknowledgment AG and JS were funded by the Wellcome Centre for Ethics and Humanities, University of Oxford, which is supported by a Wellcome Centre Grant (203132/Z/16/Z), and by the Wellcome Trust grant 104848/Z/14/Z. Through his involvement with the Murdoch Children's Research Institute, JS was supported by the Victorian Government's Operational Infrastructure Support Program. AG was also supported by the Oxford Martin School through the Oxford Martin Program on 'Collective responsibility for infectious disease'.

\section{References}

Alanis, Alfonso J. 2005. Resistance to antibiotics: Are we in the post-antibiotics era? Archives of Medical Research 36 (6): 597-705.

Anomaly, Jonny. 2009. Harm to others: The social cost of antibiotics in agriculture. Journal of Agricultural and Environmental Ethics 22: 423-435.

. 2013. Collective action and individual choice: Rethinking how we regulate narcotics and antibiotics. Journal of Medical Ethics 39: 752-756.

2019. Antibiotics and animal agriculture the need for global collective action. In Ethics and drug resistance: Collective responsibility for global public health. Cham: Springer.

Balasegaram, Manica, et al. 2015. The global innovation model for antibiotics needs reinvention. The Journal of Law, Ethics, and Medicine 43 (S3): 22-26.

Baquero, Fernando, and Jose Campos. 2003. The tragedy of the commons in antimicrobial chemotherapy. Revista espanola de quimioterapia: publicacion oficial de la Sociedad Espanola de Quimioterapia 16 (1): 11-13.

Barlam, Tamar, and Kalpana Gutpa. 2015. Antibiotic resistance spreads internationally across borders. The Journal of Law, Medicine, and Ethics 43 (S3): 12-16.

Cars, Otto, et al. 2008. Meeting the challenge of antibiotic resistance. British Medical Journal 337: 726-728.

CDC (Center for Disease Control and Prevention). About antimicrobial resistance, updated 2015. Available at: https://www.cdc.gov/drugresistance/about.html. Last access 17 Aug 2016.

CDDEP (Center for Disease Dynamics, Economics, and Policy). 2015. The state of the world's antibiotics. Available at: https://cddep.org/sites/default/files/swa_2015_final.pdf. Last access 15 Nov 2016.

Coast, J., R. Smith, and M.R. Millar. 1996. Superbugs: Should antimicrobial resistance be included as a cost in economic evaluation? Health Economics 5 (3): 217-226.

Copp, David. 2007. The collective moral autonomy thesis. Journal of Social Philosophy 38: 3.

Costelloe, Ceire, et al. 2010. Effect of antibiotic prescribing in primary care on antibiotic resistance in individual patients: Systematic review and meta-analysis. British Medical Journal 340: c2096.

Cowen, Tyler. 2008. Public goods. In The concise encyclopedia of economics, ed. R. Henderson. Indianapolis: Library of Economics and Liberty. Available at: http://www.econlib.org/library/ Enc/PublicGoods.html. Last access 5 Aug 2016.

Daulaire, Nils, et al. 2015. Universal access to effective antibiotics is essential for tackling antibiotic resistance. The Journal of Law, Medicine, and Ethics 43 (S3): 17-21.

Foster, Kevin, and Hajo Grundmann. 2006. Do we need to put society first? The potential for tragedy in antimicrobial resistance. PLoS Medicine 3 (2): 177-180.

Giubilini, A., et al. 2017. Taxing meat: Taking responsibility for one's contribution to antibiotic resistance. Journal of Agricultural and Environmental Ethics 30 (2): 179-198.

Giubilini, A., T. Douglas, J. Savulescu, and Hannah Maslen. 2018. Quarantine, isolation, and the duty of easy rescue in public health. Developing World Bioethics 18 (2): 182-189.

Hardin, Garrett. 1968. The tragedy of the commons. Science 162: 1243-1248. 
Held, Virginia. 1970. Can a random collection of individuals be morally responsible? The Journal of Philosophy 57 (14): 471-481.

Herrmann, Markus, and Ramanan Laxminarayan. 2010. Antibiotic effectiveness: New challenges in natural resource management. The Annual Review of Resource Economics 2 (4): 1-14.

Hoffman, Steven, and Trygve Ottersen. 2015. Addressing antibiotic resistance requires robust international accountability mechanisms. The Journal of Law, Medicine, and Ethics 43 (S3): 53-64.

Hoffman, Steven, et al. 2015. International law has a role to play in addressing antibiotic resistance. The Journal of Law, Medicine, and Ethics 43 (S3): 65-67.

Hollis, Aidan, and Peter Maybarduk. 2015. Antibiotic resistance is a tragedy of the commons that necessitates global cooperation. The Journal of Law, Medicine, and Ethics 43 (S3): 33-37.

Jamrozik, E., and M.J. Selgelid. Drug-resistant infection: Causes, consequences, and responses. In Ethics and drug resistance: Collective responsibility for global public health. Cham: Springer.

Klein, Eili, et al. 2018. Global increase and geographic convergence in antibiotic consumption between 2000 and 2015. In Proceedings of the National Academy of Sciences of the United States of America.

Kumar, S.G., C. Adithan, B.N. Harish, S. Sujatha, G. Roy, and A. Malini. 2013. Antimicrobial resistance in India: A review. Journal of Natural Science, Biology, and Medicine 4 (2): 286-291.

Lewis, H.D. 1948. Collective responsibility. Philosophy 23 (84): 3-18.

Littmann, J., and A.M. Viens. 2015. The ethical significance of antimicrobial resistance. Public Health Ethics 8 (3): 209-224.

Littmann, J., A. Buyx, and O. Cars. 2015. Antibiotic resistance: An ethical challenge. International Journal of Antimicrobial Agents 46: 359-361.

Miller, Seamus. 2006. Collective responsibility: An individualist account. Midwest Studies in Philosophy 30: 176-193.

Narveson, J. 2002. Collective responsibility. The Journal of Ethics 6: 179-198.

O'Neill, Jim. 2015. Antimicrobials in agriculture and the environment: Reducing unnecessary use and waste. The Review on Antimicrobials Resistance. Available at: https://amr-review.org/sites/ default/files/Antimicrobials\%20in\%20agriculture\%20and\%20the\%20environment $\% 20-\% 20$ Reducing\%20unnecessary\%20use\%20and\%20waste.pdf. Last access 8 Oct 2016.

O'Neill. 2016. Tackling drug resistant infections globally: Final report and recommendations. The Review on Antimicrobial Resistance. Available at: http://amr-review.org/sites/default/ files/160518_Final\%20paper_with\%20cover.pdf. Last access 16 Aug 2016.

Oczkowski, Simon. 2017. Antimicrobial stewardship programmes: Bedside rationing by another name? Journal of Medical Ethics 43 (10): 684-687.

Ostrom, E., J. Burger, C.B. Field, R.B. Norgaard, and D. Policansky. 1999. Sustainability Revisiting the commons: Local lessons, global challenges. Science 284: 278-282.

Podolski, Scott, et al. 2015. History teaches us that confronting antibiotic resistance requires stronger global collective action. The Journal of Law, Medicine, and Ethics 43 (S3): 27-32.

Savulescu, Julian. 2007. Future people, involuntary medical treatment in pregnancy, and the duty of easy rescue. Utilitas 19 (1): 1-20.

Scanlon, T. 1998. What We Owe to Each Other. Cambridge, MA: Harvard University Press.

Schwenkenbecher, Anne. forthcoming. Antimicrobial footprints, fairness, and collective harm. In Ethics and drug resistance: Collective responsibility for global public health. Cham: Springer.

Selgelid, M. 2007. Ethics and drug resistance. Bioethics 21 (4): 218-229.

Singer, P. 1972. Famine, affluence, and morality. Philosophy and Public Affairs 1 (3): 229-243.

Smith, Richard, and Joanna Coast. 2002. Antimicrobial resistance: A global response. Bulletin of the World Health Organization 80 (2): 126-133.

- 2003. Antimicrobial drug resistance. In Global public goods for health, ed. Smith et al., 73-93. New York: Oxford University Press.

Van der Velden, A., et al. 2013. Prescriber and patient responsibilities in treatment of acute respiratory tract infection - Essential for conservation of antibiotics. Antibiotics 2: 316-327. 
WHO. 2010. Antimicrobial resistance: Revisiting the "tragedy of the commons". Bulletin of the World Health Organization 88: 11. Available at http://www.who.int/bulletin/ volumes/88/11/10-031110/en/.

2014. Antimicrobial resistance: Global report on surveillance 2014. Geneva: World Health Organization.

. Antimicrobial resistance, Fact sheet n 194, updated 2015. Available at: http://www.who. int/mediacentre/factsheets/fs194/en/. Last access 17 Aug 2016.

WHO India. 2018. Combating antimicrobial resistance in India. Available at: http://www.searo. who.int/india/topics/antimicrobial_resistance/Combating_Antimicrobial_Resistance_in_ India/en/. Last access 19 Nov 18.

Woodward, David, and Richard D. Smith. 2003. Global public goods and health: Concepts and issues. In Global public goods for health, ed. Smith et al., 3-29. New York: Oxford University Press.

Open Access This chapter is licensed under the terms of the Creative Commons Attribution 4.0 International License (http://creativecommons.org/licenses/by/4.0/), which permits use, sharing, adaptation, distribution and reproduction in any medium or format, as long as you give appropriate credit to the original author(s) and the source, provide a link to the Creative Commons licence and indicate if changes were made.

The images or other third party material in this chapter are included in the chapter's Creative Commons licence, unless indicated otherwise in a credit line to the material. If material is not included in the chapter's Creative Commons licence and your intended use is not permitted by statutory regulation or exceeds the permitted use, you will need to obtain permission directly from the copyright holder. 